\title{
Indexed Natural Numbers in Mind: A Formal Model of the Basic Mature Number Competence
}

\author{
Wojciech Krysztofiak
}

Received: 22 November 2010/Accepted: 11 March 2011/Published online: 23 April 2011

(C) The Author(s) 2011. This article is published with open access at Springerlink.com

\begin{abstract}
The paper undertakes three interdisciplinary tasks. The first one consists in constructing a formal model of the basic arithmetic competence, that is, the competence sufficient for solving simple arithmetic story-tasks which do not require any mathematical mastery knowledge about laws, definitions and theorems. The second task is to present a generalized arithmetic theory, called the arithmetic of indexed numbers (INA). All models of the development of counting abilities presuppose the common assumption that our simple, folk arithmetic encoded linguistically in the mind is based on the linear number representation. This classical conception is rejected and a competitive hypothesis is formulated according to which the basic mature representational system of cognitive arithmetic is a structure composed of many numerical axes which possess a common constituent, namely, the numeral zero. Arithmetic of indexed numbers is just a formal tool for modelling the basic mature arithmetic competence. The third task is to develop a standpoint called temporal pluralism, which is motivated by neo-Kantian philosophy of arithmetic.
\end{abstract}

Keywords Cognitive arithmetic - Number line - Indexed natural numbers · Number-axes

\section{Introduction}

The main purpose of the article is the presentation of a formal model of the basic, mature system of cognitive arithmetic (Ashcraft 1992, 75-106; Butterworth 2005, 3-18). Cognitive arithmetic is understood as the set of systems encoded in the mind which enable us to execute numerical calculations. The empirical research

\footnotetext{
W. Krysztofiak $(\bowtie)$

Institute of Philosophy, University of Szczecin, ul. Krakowska 71-79, 71-004 Szczecin, Poland e-mail: wojciech.krysztofiak@gmail.com
} 
concerned with the representations of number seems to justify the hypothesis according to which the mathematical cognitive development of the mind passes over various phases (Wynn 1990, 155-193; Wynn 1992, 220-251). Its final phase results in the formation of the basic, mature system of the arithmetic competence due to which the mind is able to add, multiply and solve simple story-tasks in such a way that knowledge of mathematical laws, rules and theorems is not completely required for supplying solutions. In this phase children's minds come to be equipped with the representational system of the exact number. ${ }^{1}$ After acquiring this basic mature arithmetical competence, children begin their proper mathematical education aimed at developing their expert mathematical knowledge, composed of theorems, strategies and definitions, being required for solving various mathematical tasks of different levels of difficulty.

Most of cognitive psychologists seem to assume that this basic mature representational system of cognitive arithmetic is the mental number line (Dehaene 2001; Giaquinto 2001b; Carey 2001), that is, a representational structure processed by the mind during the solution of various arithmetical tasks. It functions as the representational system of exact natural numbers and as such must be distinguished from the approximate number line. ${ }^{2}$ The representational structure for exact numbers is understood in at least two main ways. In light of the first, weak Whorfian view, the origin of the natural number mental line is independent of language (Gelman and Butterworth 2005). According to the second approach, accepted by Carey (2001) and Le Corre and Carey (2007), all concepts of numbers greater than four are acquired by the mind in the processes of language acquisition. ${ }^{3}$ At any rate, this basic representational structure consists of concepts of numbers (the weak Whorfian view) or of number words with corresponding concepts (the strong Whorfian view): one, two, three, four, etc., and it is ordered by the successor function (compare: Decock 2008). Peano's arithmetic may be treated as a theory of this representational structure.

\footnotetext{
1 The representational system of the exact number is different from the representational system of the approximate number. Many researchers treat the representational system of the approximate number as rooted in cognitive evolution and hence as innate. The main difference between both representational systems is recognized in such a way that representations of approximate numbers belong to the system of core knowledge (Spelke and Kinzler 2007) whereas representations of exact numbers are encoded in minds by virtue of learning practice (De Cruz 2008). On various conceptions of acquiring the concept of natural number, see Rips et al. (2008).

2 The approximate number line possesses properties which distinguish it from the exact number line. These differences concern, especially, spatial properties and scaling properties. For instance, on the exact number line, the given absolute distance between numbers is the same on each segment of the line. In the case of the approximate number line, by contrast, an absolute distances between numbers are not the same on each segment of the line. The distance between 5 and 7 is greater than the distance between 50 and 52 . Distances on the exact number line fall under the arithmetical scale, whereas distances on the approximate number line fall under the logarithmic scale. Another distinctive feature concerns the so-called Weber-Fechner effect: The discriminability of two quantities by the use of the approximate number line is a function of their ratio, whereas the discriminability of two quantities by the use of the exact number line is independent of their ratio (Dehaene 2003; De Cruz 2008; Verguts and Fias 2008).

3 Some researchers admit that members of some indigenous social groups lack a counting system of exact numbers. In Amazonia, New Guinea and in Australia, some cultures lack numerals for numbers greater than four or five (Dixon 1980). The natural number list of numerals does not occur in the languages of these groups. They have no verbal counting routine (Pica et al. 2004). These facts are advanced as arguments for the strong Whorfian view (Dowker et al. 2008).
} 
There are at least four different paradigms for interpreting the acquisition and the origin of the exact number line. The first one is based on two non-symbolic number systems: the system of object-file representations (or the system of numerically distinct individual) and the approximate number system (Carey 2001; Spelke 2000; Le Corre and Carey 2007; Condry and Spelke 2008). The theory which accounts for the origin of the exact number line in terms of these two systems is called the parallel individuation and analog magnitudes hypothesis (Le Corre and Carey 2007). Models falling under the second paradigm assume that in the mind there is encoded a special system—called the number sense (Dehaene 1997)—responsible for non-symbolically representing large approximate numerosities. The theory of these models is called the analog magnitudes alone hypothesis (Le Corre and Carey 2007). According to the hypothesis in question, number processing is an analogical process working only upon approximate representations of numerosities (Dehaene 1997, 2001; Gallistel and Gelman 1990). Models of the third type employ the concept of scalar implicature. According to these models, children arrive at precise meanings of numerals by the use of scalar implicatures (Barner and Bachrach 2010) and quantifiers. It is worth noting that the models under discussion provide strongly Whorfian explanations of the origin of the exact number line. In accordance with them, the acquisition of the exact number line needs language and logical tools. The fourth and final paradigm is called the enriched parallel individuation alone hypothesis (Le Corre and Carey 2007). It assumes that the process of the acquisition of the exact number line consists in a bootstrapping process that employs the verbal placeholder count list and markers for small sets encoded in the mind. ${ }^{4}$

The present paper does not discuss the question of the acquisition of the counting competence. However, it should be emphasized that all the previously mentioned models of the development of counting abilities presuppose the common dogma that our simple, folk arithmetic, which is linguistically encoded in the mind, is based on linear natural number representation. In the present paper, this classical conception is rejected in favour of the competitive hypothesis according to which the basic mature representational system of cognitive arithmetic is a structure composed of many numerical axes with zero numeral as the common constituent. The formal model underlying this representational system may be illustrated with the help of the following diagram:

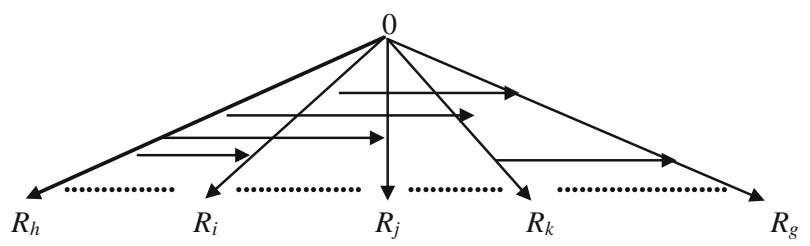

\footnotetext{
${ }^{4}$ Rips et al. (2006) criticize the view that the mechanism for acquiring the exact number line involves the procedure of inductive inference called bootstrapping. They refer to the counter-model of the bootstrapping-rule. These researchers prove that models of this rule may have a circular structure and, for instance, fall under the modular arithmetic structures $\left(\operatorname{modulo}_{10}(\mathrm{n})\right)$. The conclusion is that the bootstrapping-rule does not determine the standard model of natural numbers univocally.
} 
The vertical arrows in the diagram stand for numerical axes $R_{h}, \ldots, R_{g}$ (or lists of numerals). The bold arrow $R_{h}$ is a distinguished one. It is the basic language-axis of numerals (the verbal placeholder count list). Zero numeral is a common constituent of all axes. The horizontal arrows designate the relation of accessibility holding between axes. This relation enables the mind to find counterparts or correlates of objects from one axis on a different axis. For instance, two apples from the axis of apples may correspond to two pears from the axis of pears. The accessibility relation functions as a formal structure determining lines of correlations connecting items from different axes. If the accessibility relation holds between $R_{i}$ and $R_{j}$, it means that in the mind there is encoded an algorithm which establishes correlates on the axis $R_{j}$ of some or all items from the axis $R_{i}$. Lines of correlations may be comprehended as analogous to Hintikka's world lines. ${ }^{5}$ It should be emphasized that the accessibility relation is not intended to satisfy a semantic function of determining truth-values of arithmetical formulas. The diagrammed structure is a semantic model of the formal theory which may be named the arithmetic of indexed natural numbers (INA). INA is a generalization of Peano's arithmetic (Krysztofiak 2008).

There are educational facts which verify the presented hypothesis. Seven-year-old children are able to solve simple arithmetical story-tasks. The classical explanation of this ability presupposes that in children's minds there are encoded complex, set theoretic, distributive structures alongside the basic exact number representation upon which the mind operates to generate solutions of these story-tasks. ${ }^{6}$ To maintain this view, therefore, is to assume that some fragments of classical set theory belong either to the innate system of core knowledge or at least to the system of basic knowledge being acquired in early stages of mental development. Note that 7-yearold children are not able to express or describe the set theoretic operations allegedly being executed when they solve the story-tasks. By virtue of the assumption under discussion, however, their ability to operate upon set theoretic structures must be reputed as either an innate skill or one acquired in the early stage of mental

\footnotetext{
5 Hintikka's world lines are tools enabling the mind to identify individuals across possible worlds (Hintikka 1970a, b). The correlation lines which connect axes are, in turn, tools enabling the mind to identify correlates or equivalents of numerical items from some axes on other axes. For instance, two apples correspond to two pieces of fruit on the axis of pieces of fruit. In another situation, two apples correspond to four Euro if the price for one apple is two Euro. The correlation lines may be established in the conventional way. However, they sometimes reflect some natural relations holding between various categories of objects. Since every parrot is a bird, a correlate of two parrots on the axis of birds is two birds. In this case, the accessibility relation between the axis of parrots and the axis of birds is established in the natural way. If the accessibility relation does not hold between two axes, it means that the mind is unable to establish correlates of numerical items from the first axis on the second axis. The accessibility relation may also be comprehended in some metaphorical and metaphysical way. Numerosities determined upon a given axis (a category) may be treated as having their appearances (or guises) on other axes. For example, one person may have its appearances on the axis of legs as two legs, on the axis of fingers as ten fingers, on the axis of wages as two thousands dollars. All things being traded in barter transactions possess their appearances in their ranges of exchangeability. One slave may appear as two horses or two hundreds guns, etc. To generalize, the accessibility relation holding between axes determines a space of appearances of various numerosities correlated to a given axis. There are no naked numerosities. They are clothed in categories (in axes).

${ }^{6}$ In models of solving story-tasks proposed in (Riley et al. 1983) and in (Briars and Larkin 1984), the children's ability to manipulate set-theoretic categories belongs to the semantic stage of a strategy of solving tasks.
} 
development. In light of this conclusion, the educational process of acquiring set theory during mature professional studies should be treated as an activation or extrication from unconsciousness of formal set theoretic structures encoded in the deep strata of mind. Hence, the effectiveness of this process should be estimated as very high and 'easy'. The pedagogical experience of academic logic teachers is quite the opposite. The success rate of teaching logic and set theory to students of humanities is very low. This observation undermines the classical explanation, since the latter assumes that solving simple story-tasks involves the exercise of tacit knowledge concerned with complex set theoretic operations and structures. From the presented cluster model's point of view, by contrast, this situation may be explained in such a way that when children solve simple arithmetic story-tasks, they do not use set theory. For the aim of generating solutions to these tasks, they do not need to activate in their minds complex set theoretic representations. It is sufficient that they activate an appropriate cluster of numerical axes encoded in their minds for the purpose of supplying solutions. The lack of set theoretic representations encoded in their minds does not cause any difficulties in solving simple arithmetical story-tasks. To conclude, the difference between the standard model and the model constructed in the present paper consists in different empirical predictions. According to the first one, if seven-year-olds are not able to operate upon the following set-theoretic structures: the empty set, the sum of sets, the intersection of sets and operations of deriving complex set-theoretic operations, they are not able to solve simple storytasks. According to the second one, if seven-year-olds are not able to operate upon the following set-theoretic structures: the empty set, the sum of sets, the intersection of sets and operations of deriving complex set-theoretic operations, they are, however, able to solve simple story-tasks under the condition that their minds are equipped with a representational arithmetic system composed of many numerical axes.

The proposed formal model of basic mature arithmetic competence should be verified by some empirical data. In addition, these data should falsify the one-axis model. ${ }^{7}$ It is easy to notice that any fact of understanding complex numerals in acts

\footnotetext{
7 It should be noticed that in a volume of Behavioral and Brain Sciences comprising comments on Rips et al. (2008), none of the thirty-one entries concern the confirmation of the hypothesis according to which in the mind there is encoded exactly one number axis. Some cognitive researchers claim that the so-called experimental SNARC (Spatial Numerical Association Response Code) effects of various types may be treated as empirical evidence of the hypothesis according to which the mental representation of natural numbers possesses the shape of a line oriented from the left side to the right one. It seems that such an interpretation of SNARC experiments is not sufficiently justified. First of all, the SNARC effect only appears in the case of small Arabic numerals: from 1 to 9. In the case of illiterate Arabic speakers, the SNARC effect does not appear (Zebian 2005). Furthermore, some experiments reveal a reverse SNARC effect for Arabic monoliterates (Zebian 2005). Experiments in which the performance of a task does not require access to natural numbers semantics do not display the SNARC effect (Fias 2001). These facts may only be interpreted as confirming the hypothesis that in the literate mind there is encoded at least one mental line segment representing relatively small natural numbers whose length and spatial orientation may be different in various instances. This does not mean, however, that in all cases of number processing the mind activates exactly one mental line segment representing natural numbers. SNARC effects cannot be interpreted as evidential markers of the formal structure of the natural number representation encoded in the mind. Some researchers assert that SNARC effects confirm a thesis that the presence of the SNARC effect during number processing is a marker of the semantic number processing during number recognition. From this point of view, the absence of the SNARC effect is an index of the purely syntactic
} 
of perceiving them cannot be explained merely by reference to the semantic relations holding between digits and numbers located on the numerical axis. To understand the numeral 333, the mind has to execute many operations: (a) to refer to the third number on the axis of hundreds, (b) to refer to the third number on the axis of tens, (c) to refer to the third number on the axis of units and finally (d) to map all these numbers into the distinguished axis of all natural numbers. Let us note that the numeral 333, being comprehended in the surface way, fails to satisfy syntactic conditions of a well-formed expression on the ground of categorial grammar. Each complex expression should contain at least one functor. In the numeral 333, in its surface structure, there only occur individual expressions without functors. However, the mind does not attribute the same meaning to the digit 3 on each place of its occurrence in the numeral 333. How this is possible may be explained by attributing some tacit, deep syntactic structure to the numeral $333 .^{8}$ If the numeral 333 is to be a well-formed expression, its tacit syntactic structure should consist of at least three functors designating three axes as syntactic positions in the numeral under analysis and connecting them with the digit 3 . According to the one-axis model, positional functors hidden in deep structures of numerals must be treated as markers of some items on the axis of natural numbers. In this case, however, their semantic category cannot be distnigusihed from the semantic category of numerals. For instance, the functor of the syntactic position of tens would be interpreted as a marker of the number ten. The numeral 10 is also a marker of the number ten. In this way, the functor of the syntactic position of tens and the numeral 10 would designate the same number. According to the many-axes model proposed in the paper, such a conclusion may be avoided. ${ }^{9}$

\section{Philosophical Preliminaries}

Our minds are able to order our experiences by the use of various calendars. Systems of days in a week or in a month, or systems of months in a year, are

\section{Footnote 7 continued}

processing of numerals (Fias et al. 1996). This interpretation, however, cannot also be treated as sufficient reason for the acceptance of the thesis saying that the SNARC effect is an indice of the mental number line encoded in the mind.

8 These tacit, deep structures of numerals should be treated differently than Chomsky's deep structures of sentences. According to the Chomskian approach, any terminal constituent of a deep structure is articulated in a surface structure in the prosodic way. For example, if in a deep structure of a sentence there occurs some functor (a verb, an adjective or an adverb), it must also appear as a terminal, lexical output in a surface structure. In the case of numerals, positional functors occurring in their deep structures are not articulated in a surface structure in the prosodic way. Functors of this type may be called Jumblese predicates. In (Sellars 1962), the language of Jumblese is construed with the aim of expressing Wittgenstein's logical atomism without universals. Its peculiar feature is that all predicates occurring in sentences are represented by spatial arrangements of individual expressions. Differences in such arrangements would manifest multiplicity of Jumblese predicates. Since the linear order of digits in a numeral determines positional functors in its deep structure, it may be said that numerals possess deep Jumblese structures.

9 According to the one-axis model of natural numbers representations, it is impossible to explain how syntactic Jumblese structures of Arabic numerals designate or refer to natural numbers. 
instances of calendrical representational structures encoded in the mind. By ascribing of elements of these systems to experienced events, the mind generates in itself ordered linear representations of various histories. These calendar systems may be understood only under the condition that the mind ascribes numerals to elements of these systems (for example: Monday—one, Thuesday-two, Wednesday-three, etc.). One may call them time-forms encoded in the mind. In many cases, it seems that the mind uses multi-temporal calendars to order various experienced contents. For instance, to conceptualize various literary contents of fiction, the mind must sometimes comprehend them in a multi-temporal framework. Conceptualizing their everyday experience, people use such metaphors as double life or double home, which may be interpreted as a symptom of the mind's applying a bi-temporal cognitive form to the conceptualization of its everyday experience. Ramified computational cognitive processes exemplify the mind's entanglement in multi-temporal structures. In ramified proofs, each proof-branch constitutes a separate computational time-axis. In science, evolutionary models of life-development are presented with the help of tree-structures which may be comprehended as isomorphic with different multi-temporal structures of evolutionary ramified time. These examples of our mental activity in the domains of Ethos and Logos suggest that the time-representation encoded in the mind cannot be considered as a onetemporal structure. Hence, in light of the generative approach, the mind should be able to generate these non-linear calendric representations. This ability may be explained by reference to the cluster model of numerical axes.

Peano's arithmetic is the theory of an algebraic structure composed of the domain with the distinguished element zero and the one-placed operation of sequence. This operator is responsible for the production of the denumerable infinite set of objects with the first element and the linear order. In light of Kantian epistemology, this structure may be interpreted as the mental representation of discrete time. Moments, as elements of time, may be regarded as elements of the domain of natural numbers, and the flow of time may be represented by the operation of sequence. Acts of counting may be interpreted as acts of attributing moments to entities which belong to any domain being counted. In such a perspective, numerals appear to be markers of moments attributed to counted entities. The distinguished zero-numeral is the marker of the special moment which opens any process of counting. In light of this view, arithmetical operations should be treated as functions which attribute some moments to other moments. Hence, arithmetical theorems are descriptions of properties of these functions by virtue of which a counting subject may verify the correctness of his/her calculations.

In accordance with the Kantian view, the mind is equipped with exactly one encoded form of time which enables the cognising subject to count and compare the numerosities of various domains as well as to verify the correctness of numerical computations. This means that the mind operates with temporal structures consisting of exactly one time-axis. This claim may be baptised as temporal cognitive monism. Translated into the language of the modern cognitive debate, this means that the number sense (Dehaene 2001; Giaquinto 2001a) or, in other words, the arithmetic competence operates upon the one-axis time representation. From this point of view, our ability to detect or grasp by acquaintance approximate numerosities (Giaquinto 
2001a) consists in our capacity to estimate the approximate length of operational time needed to count those numerosities. In this case, moments on the time-axis are units of time-measure. It seems that such a paraphrase of the notion of number sense into the framework of the Kantian epistemology is justified. The Kantian a priori forms of time and space may be treated as representational systems of core knowledge. Kant's form of time is the core number representation enabling the activity of the number sense (on core knowledge, see Spelke and Kinzler 2007).

The history of mathematics shows that Kant's spatial monism can no longer be regarded as adequate. The discovery of non-Euclidean geometries may be interpreted against spatial monism. It is justified to assume that the mind is equipped with more than one spatial a priori form. In ordinary acts of comprehending empirical reality, the mind uses Euclidean space to order its various fragments. In acts of mathematical modelling some physical processes-for instance, relativistic ones-the mind must select non-Euclidean spaces. However, the point cannot be applied to arithmetic and the form of time conceived as its proper object of research, because up to the present there has not been constructed any alternative arithmetic of natural numbers.

If mentally encoded time representations are treated as number representations, then the concept of multiplicity of times should be understood as the representational structure of numerals being indexed with different time-axes. And it is obvious that such numerals cannot designate standard natural numbers. They designate indexed natural numbers which constitute a semantic model of the arithmetic of indexed numbers (INA), different from Peano's arithmetic. This difference may be expressed in such a way that in INA there occur several numbers ones, several numbers twos, several numbers threes, etc., whereas in Peano's arithmetic there exist exactly one number one, exactly one number two, exactly one number three, etc. Moreover, several different operations of addition and multiplication can be defined for indexed numbers, whereas for standard natural numbers there exist exactly one operation of addition and exactly one operation of multiplication. In terms of cognitive arithmetic, this means that the mind is equipped with a generative representation of indexed numbers which enables it to generate appropriate numeral structures (called $\boldsymbol{A C R}$-structures) which are subsequently used to solve simple arithmetical tasks. One of these $\boldsymbol{A C R}$-structures is the linear structure of standard numerals, being a special kind of indexed numerals. Standard natural numbers, however, appear to be an insufficient tool for solving simple story-tasks by seven-year-olds.

In light of Kantian epistemology, $\boldsymbol{A C R}$-structures may be interpreted as structures composed of different time series (time-axes). Each axis in any $\boldsymbol{A C R}$-structure may be interpreted as some time series encoded in the mind. $\boldsymbol{A} \boldsymbol{C R}$-structures are generated by the mind from the basic structure, which is a semantic model of INA (INA-structure) for their use in processes of solving arithmetical tasks. This structure functions as a hardware computational program which is transformed by the mind by virtue of various operations. There are two types of these operations. The former concerns time-axes and the latter deals with accessibility relations. First, the mind must distinguish time axes in a given ACR-structure and, subsequently, it 
has to impose a net of appropriate accessibility relations upon a distinguished set of time-axes.

It seems that the INA-structure is not a 'ready good' encoded in the mind. It might be suggested that the INA-structure is synthesised by the mind in at least two stages. The first stage comprises processes of building the INA-structure which result in the constitution of finite time-axes the lengths of which are determined by small numerals from zero to ten (depending on the notational system being learned by children). The distinguished language-axis (the verbal place-holder count list) in the INA-structure consists of small numerals. By generating of ACR-structures, the mind expands or prolongs the verbal place-holder count list. The mechanism of this operation may be illustrated by the following example: The mind activates the ACR-structure composed of three axes: (i) the language-axis: zero, one, two, ..., ten, (ii) the axis of units, and finally (iii) the axis of tens. When the mind activates item one on the axis of units and the item one on the axis of tens, it must subsequently map the activated complex of items onto the first axis, which is the verbal count list. Because this axis is too short, the mind is forced to expand it and introduce the numeral eleven to the language-axis. The constitution of the mature INA-structure in the mind is probably finished in some early period of children's school education. At any rate, the language-axis of the mature INA-structure is the infinite mental line of numerals. The empirical manifestation of the acquisition of this structure by a child is that he/she is able to produce any verbal numeral and any Arabic numeral (in cultures using this notational system).

Moments as constituents of time-axes in ACR-structures and in the INAstructure are tools of counting along each axis. They function as meta-representations of a subject's ostensive acts of indicating an individual object in a series of such acts. The mental representation of the numeral two on a given axis is an item representing the second act of indicating an object in any series of acts of indication. For instance, the mental representation underlying the indexed numeral two apples represents the second act of indicating an apple in a given sequence of apple indications. Hence, any time is understood as a linearly ordered meta-representational structure which comprises meta-representations of acts of indication directed towards objects of a given category. Any conscious experience of the flow of time might be explained as conditioned by processes of activation in the mind of any meta-representational time-structure. As outlined, this explanation is even compatible with the fact that the experience of the flow of time is very clear and expressive during ostensive counting of large sets of objects. To summarize, a child starts to count when his/her mind is equipped with meta-representations of ostensive acts of indication. This means that a child must first learn to control his/her acts of reference directed towards objects in the world. An execution of any act of controlling results in encoding an appropriate meta-representation. Sequences of such meta-representations are stored in an episodic memory. Their activation in the mind culminates in various experiences of the flow of time. To speak metaphorically, time-experiences map series of meta-representations of ostensive acts which are activated during our mental functioning. This means that children experience various time-series. The experience of time during counting cars parked in front of a 
building concerns a different time-sequence than the time-sequence experienced while counting the people sitting in those cars.

Combining moments by the mind along each axis consists of processes of activating successive meta-representations of appropriate acts of indication directed towards elements of a given category. A child knows that, for instance, there are three apples on a table because in his/her mind there are activated three succeeding meta-representations of acts of indicating an apple. It may be said that in some special way counting objects is the same as counting acts of reference directed towards objects. Hence, acts of counting fall under the category of acts of metareference. $^{10}$

\section{The Classical Model of Counting Abilities}

Models of counting acts executed during the solution of arithmetical story-tasks by children are constructed as experts systems on the basis of various cognitive theories which assume the existence of the counting competence encoded in the mind. These models are presented as systems simulating children's counting acts (Briars and Larkin 1984). In accordance with the main assumption underlying these models, processes of solving simple story-tasks comprise two stages: (a) a semantic analysis of the content being expressed by texts of tasks and (b) a counting process (Riley et al. 1983). The stages intertwine. In the first stage, the mind generates an arithmetic symbolic representation which takes the shape of some equation with an individual variable. The use of set theoretic categories takes place in this stage. It should be noticed that, from a logical point of view, the stages cannot be conceived as independent. Set theoretic representations formatted in the semantic stage fulfil inferential roles in the counting stage. That is why any reconstruction of cognitive recursive acts belonging to the counting stage should also comprise set theoretic representations entangled in a representational system underlying any process of solving a story-task. ${ }^{11}$ The below-presented analysis of the functioning of the

\footnotetext{
${ }^{10}$ It is possible to construct a formal model of the experiences of the flow of time. Since these experiences are evoked by processes of activation of time-axes which are, in turn, composed of moments as meta-representations of acts of indication, such a formal model should be founded on a formal model of a moment as an appropriate meta-representation encoded in the mind in some peculiar way. It seems that some phenomenological insights concerned with time-consciousness may help in formally comprehending these structures. At any rate, they must reflect retentional and protentional moments of counting acts (on formalizing phenomenological concepts, see Yoshimi 2007).

11 In Briars and Larkin (1984), a special model (CHEAPS: concrete human-like inferential problem solver) is constructed which simulates strategies for solving simple story-tasks. In the first stage, the model attributes an appropriate set theoretic category to any word of the task. For example, names of individuals, called set identifiers (Joe, Tom), may be treated as names of sets. Verbs (for instance: to give), in turn, may be translated into some set theoretic operations (increases, decreases, combinations and comparisons involving sets of objects) (Riley et al. 1983, 159). Many authors (Halberda and Feigenson 2008) emphasize that the ability to manipulate with sets, understood as "abstractions that exist in the mind", is "needed to bridge math to the world" (p. 655). These authors notice that the approximate number system and, perhaps, the exact number system are not sufficient conditions for explaining children's counting abilities. At any rate, to supply solutions of simple story-tasks, the mind must be able to operate with sets and set relational structures (Cummins 1991).
} 
classical model of counting abilities is based on the above-sketched assumptions. The aim of this analysis is to display the high level of complexity of set theoretic categories entangled in processes of solving simple story-tasks. This result motivates us to put the following question: Is it possible for seven-year-old children to have access to very sophisticated mental representations at an unconscious level, while lacking the ability to manipulate such representations consciously, as external symbolic systems?

The empirical research in cognitive linguistics, stemming from the work of Rosch (1973, 1975), shows that in everyday life, the mind does not operate with precise set theoretic categories. Children rather use prototypes to categorize their experiences. In light of this view, it would be difficult to build a model of the acquisition of set theoretic representations in the early stage of mental development. It seems that this process of acquisition takes place in the late-schooling stage of child development. Since the prototypes-representations cannot serve as tools needed to solve arithmetical story-tasks, the mental representations enabling children to solve story-tasks should be formal structures different from set theoretic formal structures.

Let us consider the following story-tasks operating in the framework of sortal count nouns:

(1) John has got one apple. Daddy gives John two apples. How many apples has John got?

(2) John has got one parrot. Daddy gives John two canaries. How many birds has John got?

(3) John has got one parrot. Daddy gives John two canaries. Mummy gives John two rabbits. How many birds has John got?

(4) John has got one apple. Daddy gives John two limes. How many sweets has John got?

What are the cognitive acts that the mind executes during the process of solving the presented story-tasks? The response to this question requires the formal reconstruction of these tasks. In the sketched manner, one may do it in the following way (where ' $\mathrm{x}_{\mathrm{a}}$ ', ' $\mathrm{x}_{\mathrm{b}}$ ' and ' $\mathrm{x}_{\mathrm{s}}$ ' are variables ranging over cardinal numbers of appropriate categories: apples, birds and sweets in John's possession):

(1) $1_{\mathrm{a}}+2_{\mathrm{a}}=\mathrm{x}_{\mathrm{a}}$

(2) $1_{\mathrm{p}}+2_{\mathrm{c}}=\mathrm{x}_{\mathrm{b}}$

(3) $1_{\mathrm{p}}+2_{\mathrm{c}}+2_{\mathrm{r}}=\mathrm{x}_{\mathrm{b}}$

(4) $1_{\mathrm{a}}+2_{1}=\mathrm{x}_{\mathrm{s}}$

In these equations, there occur indexed numerals with indexes of appropriate categories. Such expressions do not belong to the formal language of Peano's arithmetic. What kind of structures do these indexed numerals designate? The natural, intuitive answer to this question might take the following shape: Indexed numerals express the cardinalities of collections or sets marked with categories that correspond to the indices. For instance, numerals ' $1_{\mathrm{a}}$ ', ' $2_{\mathrm{c}}$ ', respectively, designate cardinal numbers of appropriate categories: one apple and two canaries. In the set theoretic language, indexed numerals may be understood as peculiar predicates 
attributed to sets. This suggests that they express properties of categorial cardinality. In this perspective, indexed numerals ' 1 a, ' 2 c' might be expressed with the use of such neologisms as one-appleness and two-canaryness. The formal definition of numerals, indexed with a category, runs as follows (where variables ' $x$ ', ' $y$ ' range over the domain of sets, the variable ' $n$ ' represents a cardinal number, and 'Card' stands for the cardinality function):

(DF 1) $n_{\mathrm{x}}(\mathrm{y}) \equiv_{\mathrm{df}}[\operatorname{Card}(\mathrm{y})=n \wedge \mathrm{y} \subset \mathrm{x}]$

The above-presented equations may be transformed, with the help of (DF 1), into the following formulas:

(1) $1_{\mathrm{a}}(\mathrm{x}) \wedge 2_{\mathrm{a}}(\mathrm{y}) \rightarrow n_{\mathrm{a}}(\mathrm{x} \cup \mathrm{y})$

(2) $1_{\mathrm{p}}(\mathrm{x}) \wedge 2_{\mathrm{c}}(\mathrm{y}) \rightarrow n_{\mathrm{b}}(\mathrm{x} \cup \mathrm{y})$

(3) $1_{\mathrm{p}}(\mathrm{x}) \wedge 2_{\mathrm{c}}(\mathrm{y}) \wedge 2_{\mathrm{r}}(\mathrm{z}) \rightarrow n_{\mathrm{b}}(\mathrm{x} \cup \mathrm{y} \cup \mathrm{z})$

(4) $1_{\mathrm{a}}(\mathrm{x}) \wedge 2_{1}(\mathrm{y}) \rightarrow n_{\mathrm{s}}(\mathrm{x} \cup \mathrm{y})$

The process of solving the analysed story-tasks consists in substituting the variable ' $n$ ' with appropriate constants in formulas (1)-(4). The solutions to the tasks are correct when formulas (1)-(4) become, by virtue of substitutions, true propositions. That is why the solutions may be presented in the following way:

(5) $\quad 1_{\mathrm{a}}(\mathrm{x}) \wedge 2_{\mathrm{a}}(\mathrm{y}) \rightarrow 3_{\mathrm{a}}(\mathrm{x} \cup \mathrm{y})$

(6) $1_{\mathrm{p}}(\mathrm{x}) \wedge 2_{\mathrm{c}}(\mathrm{y}) \rightarrow 3_{\mathrm{b}}(\mathrm{x} \cup \mathrm{y})$

(7) $1_{\mathrm{p}}(\mathrm{x}) \wedge 2_{\mathrm{c}}(\mathrm{y}) \wedge 2_{\mathrm{r}}(\mathrm{z}) \rightarrow 3_{\mathrm{b}}(\mathrm{x} \cup \mathrm{y} \cup \mathrm{z})$

(8) $1_{\mathrm{a}}(\mathrm{x}) \wedge 2_{1}(\mathrm{y}) \rightarrow 0_{\mathrm{s}}(\mathrm{x} \cup \mathrm{y})$ or $1_{\mathrm{a}}(\mathrm{x}) \wedge 2_{1}(\mathrm{y}) \rightarrow ?_{\mathrm{s}}(\mathrm{x} \cup \mathrm{y})$ (where '?' marks that the task is not solvable).

What operations the mind executes in the course of passing, respectively, from formulas (1)-(4) to propositions (5)-(8) may be decided by the reconstruction of inferential mechanisms of the following inferences:

(9) $1_{\mathrm{a}}(\mathrm{x}) \wedge 2_{\mathrm{a}}(\mathrm{y}) \vdash 3_{\mathrm{a}}(\mathrm{x} \cup \mathrm{y})$

(10) $1_{\mathrm{p}}(\mathrm{x}) \wedge 2_{\mathrm{c}}(\mathrm{y}) \vdash 3_{\mathrm{b}}(\mathrm{x} \cup \mathrm{y})$

(11) $1_{\mathrm{p}}(\mathrm{x}) \wedge 2_{\mathrm{c}}(\mathrm{y}) \wedge 2_{\mathrm{r}}(\mathrm{z}) \vdash 3_{\mathrm{b}}(\mathrm{x} \cup \mathrm{y} \cup \mathrm{z})$

(12) $1_{\mathrm{a}}(\mathrm{x}) \wedge 2_{1}(\mathrm{y}) \vdash 0_{\mathrm{s}}(\mathrm{x} \cup \mathrm{y})$

The specified inferences are enthymematic in such a way that they assume some tacit knowledge which concerns some empirical and some logical and set-theoretic relations holding between categories of the sets being counted. In all analysed inferences, the process of passing from premise to conclusion involves the use of the following definitional condition:

$$
(\mathrm{DF} 2) \mathrm{x} \cap \mathrm{y}=\varnothing \rightarrow[\operatorname{Card}(\mathrm{x})+\operatorname{Card}(\mathrm{y})=\operatorname{Card}(\mathrm{x} \cup \mathrm{y})]
$$

In all tasks, the sets upon which the mind operates to arrive at solutions are exclusive. That is why the relationship between cardinalities and sets, expressed by the condition: $\operatorname{Card}(\mathrm{x})+\operatorname{Card}(\mathrm{y})=\operatorname{Card}(\mathrm{x} \cup \mathrm{y})$, is employed by the mind in all solutions. It means that a seven-year-old child is able to map the cardinalities of set theoretic sum-constructions into the abstract model $<$ Card, $+>$. The use of (DF 2) in solving arithmetical tasks also requires two additional abilities: the capacity to 
intuitively comprehend the empty set and the ability to understand the set theoretic operation of set intersection.

Let us analyse the first task. The child's mind starts from two premises: (1) $1_{\mathrm{a}}(\mathrm{x})$, (2) $2_{\mathrm{a}}(\mathrm{y})$. Subsequently, it reads out of the content of the task the condition: (3) $\mathrm{x} \cap$ $y=\varnothing$. From (1) and (2), on the basis of the definition (DF 1), it derives that: (4) $\operatorname{Card}(\mathrm{x})=1,(5) \operatorname{Card}(\mathrm{y})=2$. By the use of (3), the child's mind counts, by means of the memory retrieval process (on models of retrieving arithmetic facts from memory, see: Lemaire et al. 1996; Ashcraft 1995), that (6) $\operatorname{Card}(\mathrm{x})+\operatorname{Card}(\mathrm{y})=$ $1+2=3$. Finally, it gives the answer: (7) $\operatorname{Card}(\mathrm{x} \cup \mathrm{y})=3$. It is easy to see that the explanation of the child's ability to solve arithmetic story-tasks of the first type, based on the classical model, works very well. To solve the first task, the subject must be acquainted with the empty set, be able to operate on set theoretic intersections and sums of sets, attribute cardinalities to denumerable sets of individuals and store simple arithmetic facts in his/her long term memory. Not all of the mentioned abilities belong to the register of basic skills classified as constitutive components of the number sense (on components of number sense see: Berch 2005). In particular, the capacity to comprehend the empty set as the result of various set theoretic operations upon sets rather belongs to the domain of sophisticated logical abilities. Hence, in order to solve the tasks of the first type, children must acquire not only their arithmetical skills but also their set theoretic, logical capacities.

The solution of the second task requires additional skills which enable the child's mind to transform predicates of categorial cardinality with some determinate indexes into predicates with different indexes. In other words, the child's mind is equipped with an inferential mechanism which is responsible for the transformation of predicates ' $1_{\mathrm{p}}$ ' and ' $2_{\mathrm{c}}$ ' into the predicate ' $3_{\mathrm{b}}$ '. When seven-year-old children are asked how they reach the solution, they usually reply that parrots and canaries are birds. Such a response indicates that they do not add sets in the standard way. They must apply another operation of summing sets. It is possible to define, on the ground of the theory of sets, the operation of sum with a categorial index.

(DF 3) $\alpha \in \mathrm{x} \cup_{\mathrm{z}} \mathrm{y} \equiv_{\mathrm{df}}(\alpha \in \mathrm{x} \cap \mathrm{z} \vee \alpha \in \mathrm{y} \cap \mathrm{z})$

$(D F 3 *): \mathrm{x} \cup \mathrm{z}$ y $=_{\mathrm{df}}[(\mathrm{x} \cap \mathrm{z}) \cup(\mathrm{y} \cap \mathrm{z})]$

Therefore, inference (10) fails to offer a precise formalization of the second task. Rather, the desired formalization should take the following form:

$\left(10^{*}\right) 1_{\mathrm{p}}(\mathrm{x}) \wedge 2_{\mathrm{c}}(\mathrm{y}) \vdash 3_{\mathrm{b}}(\mathrm{x} \cup \mathrm{b} \mathrm{y})$

When the mind solves the task, it assumes additionally that: (1) p $\subset$ b, (2) c $\subset$ b. Subsequently, it accepts premises of (10*): (3) $1_{\mathrm{p}}(\mathrm{x})$, (4) $2_{\mathrm{c}}(\mathrm{y})$. By definition (DF 1), the mind derives from (3) the following propositions: (5) $\operatorname{Card}(\mathrm{x})=1,(6) \mathrm{x} \subset \mathrm{p}$. In a similar way, from (4) it derives: (7) $\operatorname{Card}(y)=2$, (8) y $\subset$ c. From (1) and (6), by transitivity of inclusion, the mind infers: (9) x $\subset$ b and, similarly, from (2) and (8) it arrives at: (10) y $\subset$ b. On the basis of (9) and (10), respectively, there hold: (11) $\mathrm{x} \cap$ $\mathrm{b}=\mathrm{x},(12) \mathrm{y} \cap \mathrm{b}=\mathrm{y}$. Hence, by definition (DF $\left.3^{*}\right)$, it is true that: (13) $\mathrm{x} \cup \mathrm{b}=\mathrm{y}=\mathrm{x} \cup \mathrm{y}$. By the law of extensionality for identity, the mind infers the equality: (14) $3_{b}\left(x \cup_{b}\right.$ $\mathrm{y})=3_{\mathrm{b}}(\mathrm{x} \cup \mathrm{y})$. Since the task presupposes the assumption: (15) $\mathrm{x} \cap \mathrm{y}=\varnothing$, the mind infers: (16) $\operatorname{Card}(\mathrm{x} \cup \mathrm{y})=\operatorname{Card}(\mathrm{x})+\operatorname{Card}(\mathrm{y})=1+2$. By retrieving from memory 
that $1+2=3$, the child's mind gives the response that: (17) $\operatorname{Card}(\mathrm{x} \cup \mathrm{y})=3$. Finally, by virtue of (9), (10), (17) and definition (DF1), it infers that (18) $3_{b}\left(x \cup_{b} y\right)$.

In comparison with the first task, the solution of the second task requires the child's mind to construe the indexed operation of the sum. This construction involves the operation of the intersection of sets. That is why the set theoretic machinery employed by the mind to solve the second task is more complex than the set theoretic constructions used for supplying the solution of the first task. In other words, the cognitive competence needful for solving the second task involves sophisticated abilities to operate upon sets.

The set theoretic structure of the third task takes the following form:

$$
\left(11^{*}\right) 1_{\mathrm{p}}(\mathrm{x}) \wedge 2_{\mathrm{c}}(\mathrm{y}) \wedge 2_{\mathrm{r}}(\mathrm{z}) \vdash 3_{\mathrm{b}}\left(\mathrm{x} \cup \cup_{\mathrm{f}} \mathrm{y} \cup_{\mathrm{f}} \mathrm{z}\right)
$$

The tacit knowledge needed to solve this task may be expressed by formulas: (1) $\mathrm{p} \subset \mathrm{b}$, (2) $\mathrm{c} \subset \mathrm{b}$, (3) $\mathrm{r} \cap \mathrm{b}=\varnothing$. In contrast with the second task, the child's mind must comprehend that the intersection of categories of rabbits and birds is the empty set. The solution of the analysed task requires that the mind conducts the following process of deduction (the inferential mechanism is marked in brackets on the right):
(1) $\mathrm{p} \subset \mathrm{b}$
(14) $z \cap b=\varnothing$
(2) $c \subset b$
(15) $\mathrm{x} \cap \mathrm{b}=\mathrm{x}$
(3) $r \cap b=\varnothing$
premises
(16) $y \cap b=y \quad(2,11)$
(4) $1_{\mathrm{p}}(\mathrm{x})$
(17) $x \cup_{b} y \cup_{b} z=x \cup y \cup \varnothing(13,14,15,16)$
(5) $2 \mathrm{c}(\mathrm{y})$
(18) $x \cup_{b} y \cup_{b} z=x \cup y(17)$
(6) $2_{\mathrm{r}}(\mathrm{z})$
(19) $\operatorname{Card}(\mathrm{x} \cup \mathrm{b} \mathrm{y} \cup \mathrm{b} \mathrm{z})=\operatorname{Card}(\mathrm{x} \cup \mathrm{y})$
(7) $\mathrm{x} \cap \mathrm{y}=\varnothing$
(20) $\operatorname{Card}(\mathrm{x} \cup \mathrm{y})=\operatorname{Card}(\mathrm{x})+\operatorname{Card}(\mathrm{y})(\mathrm{DF} 2,7)$
(8) $\operatorname{Card}(\mathrm{x})=1 \quad($ DF 1,4$)$
(21) $\operatorname{Card}(\mathrm{x} \cup \mathrm{y})=1+2(20,8,10)$
(9) $x \subset p$
(DF 1, 4)
(22) $\quad \operatorname{Card}(\mathrm{x} \cup \mathrm{y})=3(21$, m-retrieval $)$
(10) $\operatorname{Card}(\mathrm{y})=2 \quad($ DF 1,5$)$
(23) $\quad \operatorname{Card}(\mathrm{x} \cup \mathrm{b} \mathrm{y} \cup \mathrm{b} \mathrm{z})=3(19,23)$
(11) $\mathrm{y} \subset \mathrm{c} \quad($ DF 1,5$)$
(24) $x \cup y \subset b \quad(1,9,2,11)$
(12) $\mathrm{z} \subset \mathrm{r}$
(DF 1, 6)
(13) $\mathrm{x} \cup \mathrm{b} \mathrm{y} \cup \mathrm{b} \mathrm{z}=[(\mathrm{x} \cap \mathrm{b}) \cup(\mathrm{y} \cap \mathrm{b}) \cup(\mathrm{z} \cap \mathrm{b})]$
(25) $\mathrm{x} \cup \mathrm{b} \mathrm{y} \cup \mathrm{b} \mathrm{z} \subset \mathrm{b}(24,18)$
(26) $3_{\mathrm{b}}(\mathrm{x} \cup \mathrm{b} \mathrm{y} \cup \mathrm{b} \mathrm{z})(\mathrm{DF} 1,25)$

(DF $3 *)$

The above-presented proof fails to reflect all the recursive proof-steps of the reconstructed reasoning. However, it succeeds in identifying the set theoretic abilities required for solving the task. Their formal complexity renders the task very difficult for even average adult students. Only very good pupils with special, 
above-average logical and mathematical capacities are able to generate this proof and evaluate its logical correctness. What renders the task difficult is that the set theoretic processing is united with the relevant acts of adding numbers. On the classical account, children must use not only set theory but also the arithmetic of natural numbers for the aim of supplying the solution of the task. Since the deductive process of reaching the solution comprises at least twenty six proof-steps, which are based on definitions of various complex set theoretic operations as well as on memory retrieval of numerical facts, it is difficult to explain, on the classical account, how children solve the task very quickly. The activation of mentally encoded and tacit set theoretic representations should take more time than the average time in which children actually solve the task. Moreover, outstanding adult students of logic, equipped with set theoretic definitions and theorems, need more than 5 min to execute the presented proof. Contrast this with seconds it takes some pre-school children to find the solution.

To conclude, it is obvious that the process of solving the story-tasks presented above must be founded on processing some formal representations encoded in the mind. If these representations are conceived in accordance with the classical model-that is, as set theoretic structures-then it is difficult to reconcile the following two facts: (1) that good students, after being taught logic and set theory, must put a lot of effort into formalizing analysed story-tasks, whereas they solve these tasks very quickly, that is, in seconds; and (2) that average intelligent sevenyear-old children can also solve tasks very quickly, whereas they are not able to learn logic and set theory. Therefore, it is reasonable to assume that mentally encoded formal representations needed to solve these simple story-tasks are not set theoretic structures.

The last task is peculiar because children may formulate two different though equally correct solutions. The first one-which says that the task is not solvablemay be explained in accordance with the classical model in such a way that some of the mind's inferential and generative mechanisms can be blocked if a logical independence holds between input and output representations. The process of blocking inferential mechanisms may be represented as follows (where the question mark designates that the task is not solvable):

$$
(12 *) 1_{\mathrm{a}}(\mathrm{x}) \wedge 2_{\mathrm{l}}(\mathrm{y}) \vdash ?_{\mathrm{s}}(\mathrm{z})
$$

The tacit assumptions of the task are expressed by the following formulae: (1) $\mathrm{x} \cap$ $\mathrm{s}=\varnothing,(2) \mathrm{y} \cap \mathrm{s}=\varnothing$. Since, by virtue of $?_{\mathrm{s}}(\mathrm{z})$ and definition (DF 1), it is the case that (3) $\mathrm{z} \subset \mathrm{s}$, it is evident that the cardinality of set $\mathrm{z}$ is independent of the cardinality of the input sets: $\mathrm{x}$ and $\mathrm{y}$. That is why children who assert that the task is not solvable explain their decision by saying that it is unknown how many sweets John had had before daddy gave him two limes. No implicit premises or tacit assumptions help children to find a definite response. This explanation, however, is not satisfactory, because the blockade of inferential processing caused by the lack of input information appears in the meta-inferential level of information processing, and hence may be interpreted as the manifestation of the mind's deductive competence acquired at the mastery, meta-theoretic level. 
The second solution of the task is such that John has got no sweets, which may be represented with an inference of the form:

$(12 * *) 1_{\mathrm{a}}(\mathrm{x}) \wedge 2_{1}(\mathrm{y}) \vdash 0_{\mathrm{s}}(\mathrm{x} \cup \mathrm{s} \mathrm{y})$

By virtue of (1) $\mathrm{x} \cap \mathrm{s}=\varnothing$ and (2) $\mathrm{y} \cap \mathrm{s}=\varnothing$, it follows that (3) $\mathrm{x} \cup \mathrm{s} \mathrm{y}=\varnothing$. Therefore, (4) $\operatorname{Card}(\mathrm{x} \cup \mathrm{s} \mathrm{y})=0$. On the basis of (3) and the law (5) $\varnothing \subset \mathrm{s}$, the mind infers that (6) $0_{\mathrm{s}}(\mathrm{x} \cup \mathrm{s} \mathrm{y})$. It is worth noticing that the premises of the inference $(12 * *)$ are irrelevant to its logical correctness. The disadvantage of this explanation resolves itself to the conclusion that the empty set of sweets is a result of applying the operation $\cup_{\mathrm{s}}$ to the input sets $\mathrm{x}$ and $\mathrm{y}$.

It is easy to see that the two alternative solutions are founded upon different formal conceptualizations of the output set. In the first case, the output set does not result from the operation of $\cup_{s}$ applied to the input sets. In the second case, conceptualization of the output set depends on the input sets. Hence, the following issue arises: what are the causes of these different formal conceptualizations of the task in children's minds? It seems that the classical model prefers the second conceptualization because of its compatibility with conceptualizations of tasks from (1) to (3). However, this situation requires seven-year-old children to operate upon the empty set in a very sophisticated way.

\section{Basic Mature Numerical Abilities in Light of the Arithmetic of Indexed Natural Numbers}

A child's numerical abilities may be explained as being founded on the processing of a special arithmetic structure here referred to as the cluster of numerical axes. The theory of such a structure is the arithmetic of indexed natural numbers (INA) (Krysztofiak 2008). By virtue of various extensions of INA, the mind transforms the input cluster of numerical axes into the structures which function as arithmetic cognitive representations (ACR-structures) underlying the contents of different arithmetical story-tasks being solved by children. In other words, the input structure functions as a generator of $\boldsymbol{A C R}$-structures relevant for various computational aims settled in story-tasks.

\subsection{The Arithmetic of Indexed Natural Numbers}

The language of INA comprises the following primitive syntactic categories of expressions: (1) standard expressions of the second order predicate calculus with identity and functions; (2) individual variables ranging over the set of moments (understood as tools of counting): $\mathrm{x}, \mathrm{y}, \mathrm{z}$; (3) the individual constant $\mathbf{0}$ and individual constants standing for moments: $\mathbf{x}, \mathbf{y}, \mathbf{z}$; (4) function variables ranging over a set of numerical axes: i, j, k, 1, m, called variable indices; (5) function constants which designate time-axes: $\mathbf{i}, \mathbf{j}, \mathbf{k}, \mathbf{l}, \mathbf{m}$, called constant indices; (6) the predicate $\mathrm{N}$ which expresses the property of being an indexed natural number; (7) the function $\mathrm{S}$ which forms with indices (variables or constants) expressions of indexed functions of sequence: $S_{i}, S_{i}, S_{j}, S_{j}$, etc.; (8) numeral constants which 
designate indexed natural numbers (these constants are introduced to the system by definitions): $1_{\mathbf{i}}, 1_{\mathbf{j}}, 2_{\mathbf{i}}, 2_{\mathbf{j}}$, etc.; (9) numeral variables: $1_{\mathbf{i}}, 1_{\mathbf{j}}, 2_{\mathrm{i}}, 2_{\mathrm{j}}$, etc. (the low indices in these expressions are variable indices, in contrast to numeral constants in which indices are constant indices); (10) standard brackets used in predicative contexts and square brackets used in function contexts.

The language of INA comprises two distinct syntactic categories of individual expressions. The first category $\boldsymbol{P}$ embraces expressions of two types: (2) and (3). Expressions in category $\boldsymbol{P}$ serve as tools for representing moments. The second category of individual expressions is a derivative one. Its elements are called numeral expressions. This category is designated by the letter $\boldsymbol{L}$. The definition of $\boldsymbol{L}$ requires the use of the category of indices $\boldsymbol{I}$ to which there belong expressions of two types: (4) and (5), and additionally the category of expressions representing indexed functions of sequence. Let the letter $\boldsymbol{F}$ be the name of this category. The category $\boldsymbol{L}$ is defined in the following way:

(Df. $\boldsymbol{L}) \quad$ (i) $\alpha \in \boldsymbol{P} \wedge \beta \in \boldsymbol{I} \rightarrow \beta[\alpha] \in \boldsymbol{L}$

(ii) $\alpha \in \boldsymbol{L} \wedge \beta \in \boldsymbol{F} \rightarrow \beta[\alpha] \in \boldsymbol{L}$

Numeral expressions are intended to represent or designate indexed natural numbers. These objects are values of indices which, in turn, are considered as functions representing numerical axes. The arguments of these functions are moments represented or designated by expressions belonging to the category $\boldsymbol{P}$. In light of the second condition in (Df $\boldsymbol{L}$ ), indexed natural numbers are also values of indexed functions of sequence applied to indexed natural numbers. In accordance with (i), expressions of the shape: $\mathrm{i}[\mathrm{x}], \mathrm{i}[0], \mathrm{i}[\mathrm{x}], \mathrm{i}[0], \mathrm{i}[\mathbf{x}]$, are numeral expressions. In light of (ii), if any indexed function of sequence is applied to expressions of the above-mentioned shapes, the resulting expressions, such as: $\mathrm{S}_{\mathrm{i}}[\mathrm{i}[\mathrm{x}]], \mathrm{S}_{\mathrm{i}}[\mathrm{i}[\mathrm{x}]], \mathrm{S}_{\mathrm{j}}[\mathrm{i}[\mathrm{x}]], \mathrm{S}_{\mathrm{i}}[\mathrm{i}[\mathrm{x}]]$, etc., are also numeral expressions. Furthermore, since indexed functions of sequence may be iterated, expressions of the shape: $\mathrm{S}_{\mathrm{i}} \mathrm{S}_{\mathrm{i}}[\mathrm{i}[\mathrm{x}]], \mathrm{S}_{\mathrm{i}} \mathrm{S}_{\mathrm{i}}[\mathrm{i}[0]], \mathrm{S}_{\mathrm{i}} \mathrm{S}_{\mathrm{j}}[\mathrm{i}[\mathrm{x}]], \mathrm{S}_{\mathrm{i}} \mathrm{S}_{\mathrm{j}}[\mathrm{i}[\mathrm{x}]], \mathrm{S}_{\mathrm{i}} \mathrm{S}_{\mathrm{j}}[\mathrm{i}[\mathrm{x}]]$, etc., are also numeral expressions.

Because numerals may be very long expressions composed, for instance, of a million iterations of the indexed function of sequence, one may introduce into the language of INA definitions of their numeral abbreviations which are divided into two types: numeral constants and numeral variables. Numeral constants are defined as follows: $0_{\mathbf{i}}=\mathbf{i}[0], 1_{\mathbf{i}}=\mathrm{S}_{\mathbf{i}}[\mathbf{i}[0]], 2_{\mathbf{i}}=\mathrm{S}_{\mathbf{i}} \mathrm{S}_{\mathbf{i}}[\mathbf{i}[0]], 3_{\mathbf{i}}=\mathrm{S}_{\mathbf{i}} \mathrm{S}_{\mathbf{i}} \mathrm{S}_{\mathbf{i}}[\mathbf{i}[0]]$, etc. Numeral variables are introduced into the system by definitions of the following shapes: $0_{\mathrm{i}}=\mathrm{i}[0], 1_{\mathrm{i}}=\mathrm{S}_{\mathrm{i}}[\mathrm{i}[0]], 2_{\mathrm{i}}=\mathrm{S}_{\mathrm{i}} \mathrm{S}_{\mathrm{i}}[\mathrm{i}[0]], 3_{\mathrm{i}}=\mathrm{S}_{\mathrm{i}} \mathrm{S}_{\mathrm{i}} \mathrm{S}_{\mathrm{i}}[\mathrm{i}[0]]$, etc. For example, the difference between numerals ' $1_{i}$ ' and ' $1_{\mathbf{i}}$ ' resolves itself into that the first numeral is a variable ranging over the set of indexed natural numbers which occupy the first location after zero on any numerical axis, whereas the second numeral designates the settled indexed number which occupies the first location after zero on the numerical axis $\mathbf{i}$.

The axiomatic of INA comprises three types of axioms: (i) axioms which characterise categories of moments and numerical axes without reference to indexed functions of sequence, (ii) axioms which establish properties of indexed functions of sequence, and finally, (iii) axioms which define various operations upon indexed natural numbers. 
$(\mathrm{A} 1)(\forall \mathrm{i})(\forall \mathrm{j}) \mathrm{i}[0]=\mathrm{j}[0]$

(A2) $(\forall \mathrm{i})(\forall \mathrm{j})(\forall \mathrm{x})(\mathrm{x} \neq 0 \wedge \mathrm{i} \neq \mathrm{j} \rightarrow \mathrm{i}[\mathrm{x}] \neq \mathrm{j}[\mathrm{x}])$

$(\mathrm{A} 3)(\forall \mathrm{i})(\forall \mathrm{j})(\forall \mathrm{x})(\forall \mathrm{y})(\mathrm{i}[\mathrm{x}]=\mathrm{j}[\mathrm{y}] \rightarrow \mathrm{x}=\mathrm{y})$

(A4) $(\forall \mathrm{i})(\forall \mathrm{x}) \mathrm{N}(\mathrm{i}[\mathrm{x}])$

(A5) $(\forall \mathrm{i})(\forall \mathrm{x})(\exists \mathrm{y}) \mathrm{S}_{\mathrm{i}}[\mathrm{i}[\mathrm{x}]]=\mathrm{i}[\mathrm{y}]$

(A6) $(\forall \mathrm{i})(\forall \mathrm{j})(\forall \mathrm{x})\left(\mathrm{i} \neq \mathrm{j} \rightarrow \mathrm{S}_{\mathrm{i}}[\mathrm{j}[\mathrm{x}]]=\mathrm{i}[0]\right)$

(A7) $(\forall \mathrm{i})(\forall \mathrm{x}) \mathrm{S}_{\mathrm{i}}[\mathrm{i}[\mathrm{x}]] \neq \mathrm{i}[0]$

$\left(\right.$ A8) $(\forall \mathrm{i})(\forall \mathrm{x})(\forall \mathrm{y})\left(\mathrm{S}_{\mathrm{i}}[\mathrm{i}[\mathrm{x}]]=\mathrm{S}_{\mathrm{i}}[\mathrm{i}[\mathrm{y}]] \rightarrow \mathrm{i}[\mathrm{x}]=\mathrm{i}[\mathrm{y}]\right)$

(A9) $(\forall \mathrm{i})\left\{\Psi(0) \wedge(\forall \mathrm{x})\left(\Psi(\mathrm{i}[\mathrm{x}]) \rightarrow \Psi\left(\mathrm{S}_{\mathrm{i}}[\mathrm{i}[\mathrm{x}]]\right)\right) \rightarrow(\forall \mathrm{x}) \Psi(\mathrm{i}[\mathrm{x}])\right\}$

Axiom (A1) expresses the idea that all numerical axes originate from a common number, namely the number zero. Axiom (A2) asserts that two numbers with different indices, if they are not identical with zero, are different numbers. For instance, if there are given two numerical axes, namely the axis of apples and the axis of sweets, then, in accordance with (A2), two-appleness and two-sweetness are different indexed natural numbers. Axiom (A3) establishes that if two indexed natural numbers are one and the same number, then arguments of given indices in numbers must be also identical. Axiom (A4) says that every object located on any numerical axis generates an indexed natural number. According to axiom (A5), any i-function of sequence always assigns some i-indexed number to any i-indexed number. This means that indexed functions of sequence do not produce values outside their corresponding numerical axes. By virtue of axiom (A6), if any $\mathrm{i}$-function of sequence is applied to indexed natural numbers belonging to numerical axes other than the i-th numerical axis, then the value of the i-function of sequence is zero. In other words, (A6) expresses the intuition that it is inappropriate to apply a function of sequence, correlated to a given axis, to any number belonging to a different axis. This inappropriateness is marked in such a way that the result of the improper application of any function of sequence is always zero. In axiom (A7), it is settled that the number $\mathrm{i}[0]$ is not a successor of any number on i-th axis. Axiom (A8) establishes that any function of sequence in the range of appropriate applications is a one-to-one function. Axiom (A9) is the principle of induction and as such is the schema of axioms. For each axis, if it is the case that zero satisfies some propositional function $\Psi(\ldots)$ and if it is the case that if every number from a given axis satisfies the propositional function $\Psi(\ldots)$, then the successor of this number also satisfies the propositional function $\Psi(\ldots)$, then every number from a given axis satisfies the propositional function $\Psi(\ldots)$.

In the arithmetic INA there may be defined many various indexed operations: indexed addition, indexed multiplication, involution, subtraction, factorial, etc. Standard operations upon natural numbers, defined in Peano's arithmetic, appear to be special cases of corresponding indexed operations upon indexed natural numbers under the condition that all indexes in a formula are identical. For the sake of the present paper, only the operation of indexed addition is introduced. The definition employs the notion of correspondence between axes. The operation of addition may be executed on various axes. Numbers from different axes may be added on another axis. For instance, the number of canaries and the number of parrots may be added on the axis of birds. In this case, the correspondence between the axis of canaries 
and the axis of parrots is of the type, one canary-to-one parrot. However, in other cases, this relation may fall under a different pattern. For instance, one man may correspond to ten fingers and one car to four persons. When the mind's task is, for example, to count the number of persons in four full cars, first it must find the counterpart of the indexed number one-carness on the axis of persons. In this way, when the mind adds two cars to three cars and counts the number of persons, it must execute the addition of cars on the axis of persons. In any case, the correspondence function may be different. This function is assumed by the mind on the basis of empirical or conventional rules. Let $\mathrm{Cor}_{\mathrm{k}}$ be the function of correspondence on the axis $\mathrm{k}$. This means that Cor $_{\mathrm{k}}$ returns values of indexed numbers from various axes on the axis $\mathrm{k}$. The definition of k-indexed addition runs as follows:

$$
\begin{array}{ll}
\left(\mathrm{DF}+_{\mathrm{k}}\right) & \text { (1) } \mathrm{k}[0]+_{\mathrm{k}} \mathrm{k}[\mathrm{x}]=\mathrm{k}[\mathrm{x}] \\
& \text { (2) } \mathrm{S}_{\mathrm{k}}[\mathrm{k}[\mathrm{x}]]+{ }_{\mathrm{k}} \mathrm{k}[\mathrm{y}]=\mathrm{S}_{\mathrm{k}}\left[\mathrm{k}[\mathrm{x}]+_{\mathrm{k}} \mathrm{k}[\mathrm{y}]\right] \\
& \text { (3) } \mathrm{i}[\mathrm{x}]+_{\mathrm{k}} \mathrm{j}[\mathrm{y}]=\operatorname{Cor}_{\mathrm{k}}(\mathrm{i}[\mathrm{x}])+_{\mathrm{k}} \operatorname{Cor}_{\mathrm{k}}(\mathrm{j}[\mathrm{y}])
\end{array}
$$

For example, the calculation: one canary plus one parrot on the axis of birds $\left(1_{\mathbf{c}}+_{\mathbf{b}}\right.$ $\left.1_{\mathbf{p}}\right)$, proceeds in accordance with the following recursive schema: $1_{\mathbf{c}}+_{\mathbf{b}}$ $1_{\mathbf{p}}=\operatorname{Cor}_{\mathbf{b}}\left(1_{\mathbf{c}}\right)+_{\mathbf{b}} \operatorname{Cor}_{\mathbf{b}}\left(1_{\mathbf{p}}\right)=1_{\mathbf{b}}+{ }_{\mathbf{b}} 1_{\mathbf{b}}=\mathrm{S}_{\mathbf{b}}\left(0_{\mathbf{b}}+_{\mathbf{b}} 1_{\mathbf{b}}\right)=\mathrm{S}_{\mathbf{b}}\left(1_{\mathbf{b}}\right)=2_{\mathbf{b}}$.

\subsection{Generation of Arithmetic Cognitive Representations}

Arithmetic cognitive representations are structures founded upon semantic models of INA. These models have shapes falling under clusters of infinite axes. The number of axes in a model is not determinate. In the ultimate case, semantic models of INA consist of exactly one axis. By analogy to Chomsky's generativism, these models may be treated as deep arithmetic representations. To solve an arithmetical task, the mind must accommodate one of these models to the content of the task. This process of accommodation eventuates in generation of a new structure, called the arithmetic cognitive representation, whose function is to represent the task in the mind. Such arithmetic cognitive representations may be called, by analogy to the Chomskian approach, deep arithmetic representations. ${ }^{12}$

Let $\boldsymbol{A C R}$ be any arithmetic cognitive representation. It may be defined as an n-tuple of the form: $\langle\boldsymbol{I N A}, \boldsymbol{U}, \mathbf{I}, \boldsymbol{A c c}, \boldsymbol{C O R}>$, where $\boldsymbol{I N A}$ is any semantic model of INA (indexed numbers arithmetic), $\boldsymbol{U}$ is the set of some axes belonging to INA, I is the distinguished axis, called the linguistic line of numerals, Acc is the accessibility relation determined upon elements of $\boldsymbol{U}$ and $\boldsymbol{C O} \boldsymbol{R}$ is the set of all functions of correlation between indexed numbers from axes belonging to $\boldsymbol{U}$. Any structure of the form: $\langle\boldsymbol{I N A}, \boldsymbol{U}, \mathbf{I}, \boldsymbol{A c c}, \boldsymbol{C O R}>$, must satisfy the following minimal conditions:

\footnotetext{
12 In some theories of mathematical thinking, motivated by the constructivist paradigm, the mathematical cognitive development of the mind is comprehended as stemming from deep intuitions of mathematical concepts. These intuitions supply us with stable and context-independent meanings. Moreover, these intuitions may work in our minds without definitions of mathematical concepts. 'Deep intuitions are not separate mental objects; they are parts of various heterogeneous systems and form intricate webs' (Semadeni 2008, 9).
} 

(C1) $\mathbf{I} \in \boldsymbol{U}$
(C2) $(\forall \mathrm{i})[\mathrm{i} \in \boldsymbol{U} \rightarrow \mathrm{i}$ Acc i]
(C3) $(\forall \mathrm{i})[\mathrm{i} \in \boldsymbol{U} \rightarrow \mathbf{I}$ Acc i]
(C4) $(\forall \mathrm{i})(\forall \mathrm{j})(\forall \mathrm{k})[\mathrm{i} \in \boldsymbol{U} \wedge \mathrm{j} \in \boldsymbol{U} \wedge \mathrm{k} \in \boldsymbol{U} \rightarrow(\mathrm{i}$ Acc j $\wedge$ j Acc $\mathrm{k} \rightarrow \mathrm{i}$ Acc k) $]$
(C5) $(\forall \mathrm{i})(\forall \mathrm{j})\left[\mathrm{i} \in \boldsymbol{U} \wedge \mathrm{j} \in \boldsymbol{U} \rightarrow\left(\mathrm{i} \boldsymbol{A c c} \mathrm{j} \rightarrow(\forall \mathrm{x})(\exists \mathrm{y}) \operatorname{Cor}_{\mathrm{j}}(\mathrm{i}[\mathrm{x}])=\mathrm{j}[\mathrm{y}]\right)\right]$
(C6) $(\forall \mathrm{i})(\forall \mathrm{j})\left[\mathrm{i} \in \boldsymbol{U} \wedge \mathrm{j} \in \boldsymbol{U} \rightarrow\left(\sim \mathrm{i} \operatorname{Acc} \mathrm{j} \rightarrow(\forall \mathrm{x}) \operatorname{Cor}_{\mathrm{j}}(\mathrm{i}[\mathrm{x}])=\mathrm{j}[0]\right)\right]$

The distinguished axis I consists of numerals: one, two, three, etc. Its elements are classical numerals. In various languages or codes they are expressed by different words or signs. This axis is a tool for counting various indexed numerosities. When the mind counts sweets in a box, it maps numerals from the distinguished axis into the axis of sweets. In this way, the indexed number $2_{\mathbf{s}}$ is the result of mapping the numeral two from the axis $\mathbf{I}$ into the second point (moment) of the axis of sweets. Condition (C3) expresses the idea that every axis of the set $U$ is accessible from the axis $\mathbf{I}$. This means that each axis belonging to $\boldsymbol{U}$ can be counted with numerals from the axis I. Conditions (C2) and (C4) put the properties of reflexivity and transitivity on the relation of accessibility. Condition (C5) establishes the connection between the relation of accessibility and the function of correlation. If an axis is accessible from another axis, any number of the axis which is an argument of the relation of accessibility possesses its counterpart on the accessible axis. Condition (C6) asserts that if some axis is not accessible from another axis, then for each number from the axis on the input, its counterpart on the axis on the output is zero. For instance, the counterpart of the number two-appleness on the axis of animals may be zeroanimalness in some cognitive arithmetic representations. It is obvious that in some arithmetic representational structures, two-appleness may be correlated to oneanimalness (for example, in story-tasks where every animal eats two apples for breakfast). These correlations are expressed by conventional rules or some empirical postulates which constitute our common knowledge. These rules or postulates may take various shapes: one car means four persons, one hand means five fingers, one woman is worth of four oxen (Homer's example from Iliad). The accessibility relations holding between axes in any $\boldsymbol{A} \boldsymbol{C} \boldsymbol{R}$-structure are determined by such correlations. This means that the settlement of the accessibility relation in a given $\boldsymbol{A C R}$-structure underlying a given story-task is mediated by our common knowledge.

$\boldsymbol{A C R}$-structures may satisfy additional conditions as well. Some of these facultative conditions may establish the number of axes in a given $\boldsymbol{A C R}$-structure. The process of generating an $\boldsymbol{A} \boldsymbol{C} \boldsymbol{R}$-structure comprises: (1) the acquisition of the linguistic line of numerals I, (2) the constitution of appropriate axes in the mind, (3) the settlement of the relation of accessibility between axes and, finally, (4) the construction of functions of correlations for indexed numbers from these axes.

Consider the first story-task analysed above. Its corresponding $\boldsymbol{A C R}$-structure takes the following shape: $\langle\boldsymbol{I N A} \boldsymbol{A}, \boldsymbol{U}, \mathbf{I}, \boldsymbol{A c c}, \boldsymbol{C O R}>$, where (1) $\boldsymbol{U}=\{\mathbf{I}, \mathbf{a}\}$, (2) ( $\forall \mathrm{x}$ ) $\operatorname{Cor}_{\mathbf{a}}(\mathbf{I}[\mathrm{x}])=\mathrm{x}_{\mathbf{a}}$. Hence, the arithmetic cognitive representation needed to solve the first task is the cluster of two axes: the linguistic line of numerals and the axis of apples. The first stage in solving the task is the derivation of the representational structure with a numerical variable from the $\boldsymbol{A} \boldsymbol{C R}$-structure: (1) $1_{\mathbf{a}}+{ }_{\mathbf{a}} 2_{\mathbf{a}}=\mathrm{x}_{\mathbf{a}}$. The 
subsequent stage consists in retrieving from memory the fact: (2) ( $\forall \mathrm{i}) 1_{\mathrm{i}}+_{\mathrm{i}} 2_{\mathrm{i}}=3_{\mathrm{i}}$. Substituting the variable $i$ in (2) with the constant $\mathbf{a}$, the mind receives the result: (3) $1_{\mathbf{a}}+{ }_{\mathbf{a}} 2_{\mathbf{a}}=3_{\mathbf{a}}$

Solving the second story-task, the mind generates an $\boldsymbol{A C R}$-structure with four axes: $\boldsymbol{U}=\{\mathbf{I}, \mathbf{p}, \mathbf{c}, \mathbf{b}\}$. It establishes the relation of accessibility by virtue of the empirical knowledge: (1) p Acc b, (2) $\mathbf{c} \boldsymbol{A c c} \mathbf{b}$ (because parrots and canaries are birds). Subsequently, the mind construes, on the basis of his/her common knowledge, one function of correlation $\mathrm{Cor}_{\mathbf{b}}$ in accordance with the following pattern: (3) $(\forall x) \operatorname{Cor}_{\mathbf{b}}(\mathbf{p}[\mathrm{x}])=\mathrm{x}_{\mathbf{b}},(4)(\forall \mathrm{x}) \operatorname{Cor}_{\mathbf{b}}(\mathbf{c}[\mathrm{x}])=\mathrm{x}_{\mathbf{b}}$. In the first stage of solving the task, the mind generates from the $\boldsymbol{A C R}$-structure a representational structure with a numerical variable: (5) $1_{\mathbf{p}}+_{\mathbf{b}} 2_{\mathbf{c}}=\mathrm{x}_{\mathbf{b}}$. In the succeeding step, the mind applies to (5) the third condition from the definition of addition (DF $+_{k}$ ). In this way, the structure (5) is transformed into the structure: (6) $\operatorname{Cor}_{\mathbf{b}}(\mathbf{p}[1])+_{\mathbf{b}}$ $\operatorname{Cor}_{\mathbf{b}}(\mathbf{c}[2])=\mathrm{x}_{\mathbf{b}}$. By virtue of (1), (3) and (2), (4), the mind derives from (6) the structure: (7) $1_{\mathbf{b}}+_{\mathbf{b}} 2_{\mathbf{b}}=x_{\mathbf{b}}$. Finally, by retrieving from memory the fact: (8) ( $\left.\forall \mathrm{i}\right) 1_{\mathrm{i}}$ $+_{i} 2_{i}=3_{i}$, (7) is transformed into the ultimate result: $1_{\mathbf{b}}+_{\mathbf{b}} 2_{\mathbf{b}}=3_{\mathbf{b}}$. In the case of the second task, the mind does not operate upon set theoretic categorial structures. Cognitive set theoretic competence is not required for the solution of the second task.

The third story-task motivates the mind to generate an $\boldsymbol{A C R}$-structure with five axes: $\boldsymbol{U}=\{\mathbf{I}, \mathbf{p}, \mathbf{c}, \mathbf{r}, \mathbf{b}\}$. In this structure, the relation of accessibility is settled in the following way: (1) p Acc b, (2) $\mathbf{c} \boldsymbol{A c c} \mathbf{b}$, (3) $\sim \mathbf{r} \boldsymbol{A c c} \mathbf{b}$. The function of correlation is construed by the mind as in the second task: (4) $(\forall \mathrm{x}) \operatorname{Cor}_{\mathbf{b}}(\mathbf{p}[\mathrm{x}])=\mathrm{x}_{\mathbf{b}}$, (5) $(\forall \mathrm{x}) \operatorname{Cor}_{\mathbf{b}}(\mathbf{c}[\mathrm{x}])=\mathrm{x}_{\mathbf{b}}$. In the next step, the mind generates, on the basis of the $\boldsymbol{A C R}$-structure, a representational structure which takes the form: (6) $\left(1_{\mathbf{p}}+_{\mathbf{b}} 2_{\mathbf{c}}\right)+_{\mathbf{b}}$ $2_{\mathbf{r}}=\mathrm{x}_{\mathbf{b}}$. By the use of (1), (4) and (2), (5), the mind infers from (6) the structure: (7) $\left(1_{\mathbf{b}}+_{\mathbf{b}} 2_{\mathbf{b}}\right)+_{\mathbf{b}} 2_{\mathbf{r}}=\mathbf{x}_{\mathbf{b}}$. The succeeding step consists in applying (3) together with condition (C6) to structure (7). In this way, the mind derives: (8) $\left(1_{\mathbf{b}}+_{\mathbf{b}} 2_{\mathbf{b}}\right)+_{\mathbf{b}}$ $0_{\mathbf{b}}=\mathrm{x}_{\mathbf{b}}$. By retrieving from the memory the appropriate arithmetical fact, the mind deduces: (9) $3_{\mathbf{b}}+{ }_{\mathbf{b}} 0_{\mathbf{b}}=\mathbf{x}_{\mathbf{b}}$. In the final stage of solving the task, by retrieving from memory the fact that three plus zero is three, the mind derives: (10) $3_{\mathbf{b}}+_{\mathbf{b}} 0_{\mathbf{b}}=3_{\mathbf{b}}$. In comparison with the classical model which attempts to explain children's ability to effectively solve the analysed task, the presented model of indexed natural numbers shortens the algorithmic time needed to solve the task. The abovereconstructed proof of the solution of the third task shows that the algorithmic time, being represented by proof-steps, is rather long. Additionally, the time needed to retrieve set theoretic operational knowledge must also prolong the process of solving the task. This conclusion, however, is incompatible with the fact that standard seven-year-old children usually solve the task very fast. Hence, in comparison with the classical model, the model of indexed numbers offers a better explanation of the length of algorithmic processing time needed for the mind to supply the solution of the task.

The $\boldsymbol{A C R}$-structure for the fourth task comprises four axes: $\boldsymbol{U}=\{\mathbf{I}, \mathbf{a}, \mathbf{l}, \mathbf{s}\}$. The relation of accessibility is established only in accordance with condition (C3). Furthermore, there hold the following relations: (1) a Acc s, (2) I Acc s (because neither apples nor limes are sweets). In the subsequent step, the mind derives a 
representational structure of the shape: (3) $1_{\mathbf{a}}+_{\mathbf{s}} 2_{\mathbf{l}}=\mathrm{x}_{\mathbf{s}}$. By virtue of (1), (2) and condition (C6), the mind transforms (3) into: (4) $0_{\mathbf{s}}+{ }_{\mathbf{s}} 0_{\mathbf{s}}=\mathrm{x}_{\mathbf{s}}$. By retrieving from memory the fact that zero plus zero is zero, the mind gives the solution: (5) $0_{\mathbf{s}}+_{\mathbf{s}}$ $0_{\mathbf{s}}=0_{\mathbf{s}}$. The presented model, contrary to the classical model, excludes the correctness of one of the two alternative solutions discussed above, that is, the one according to which the task is not decidable. This divergence may be easily explained. The notions of the solvability and unsolvability of arithmetical tasks are acquired by the mind by virtue of very sophisticated learning processes. Hence, only outstanding children with special mathematical skills are able to give the result that the task is unsolvable. In this case, it may be assumed that they are using a strategy based on set theory to solve the task. Normal children, however, give the solution for the fourth task that John has got zero sweets. The time needed to supply the solution is relatively short for this task. The classical model predicts that this time should be relatively long because of the number of proof steps required to achieve the solution.

\section{Concluding Notes}

The present paper fulfils three main aims. First, it presents a formal model of the arithmetic competence acquired by children in the process of early school education. This model explains arithmetic skills in a quite different way than the classical model based on Peano's arithmetic and set theory. The novelty of the proposed approach is the use of the arithmetic of indexed natural numbers, which is a generalization of Peano's arithmetic. In this way, the paper fulfils its second aim to present some arithmetic theory which describes the peculiar structure of numbers. Peano's natural numbers may be defined as special cases of indexed natural numbers. This takes place when the cluster of number axes consists of exactly one axis. The third aim has been to display the importance of the Kantian point of view in the field of mathematics, that is, the importance of the idea of arithmetic as the theory of time. This point may be enriched with some phenomenological insights concerned with time-consciousness. Not only in logic is it possible to model the formal properties of various types of time. It is also possible to do it in the arithmetic of indexed natural numbers.

In the recent debate on the acquisition of counting abilities, the main controversy is concerned with the role of the approximate number representations in this process. If one assumes that children's counting acts, in the early, pre-school stage of their arithmetical development, are not directed referentially towards objects being counted, but that they are ostensive acts of naming them with numerals, then one may interpret counting as a meta-process of counting ostensive acts of indicating objects. In other words, when a child counts sweets on a table, he/she counts his/her own acts of indicating sweets by the use of numerals from the verbal number list. In this way, number axes may be comprehended as representations of operational time-axes. The result of the child's counting - that is, that on a table there are four sweets-would mean that the time needed to count them is determined by four successive acts of ostensive indication. In light of this 
neo-Kantian perspective, skills which involve counting with exact numbers are founded upon our reflexive capacity for the exact estimation of operational lengths of times needed for the ostensive enumeration of all elements of a given set, whereas the number sense, understood as a competence operating upon approximate numbers, is a cognitive ability directed intentionally towards numerosities of sets in the experienced world. Approximate numbers are properties of experienced sets comprised by the world, whereas exact numbers are properties of operational times needed for the execution of the complete enumeration of a set. This difference justifies the conjecture that representations of exact numbers cannot be derived from representations of approximate numbers.

Open Access This article is distributed under the terms of the Creative Commons Attribution Noncommercial License which permits any noncommercial use, distribution, and reproduction in any medium, provided the original author(s) and source are credited.

\section{References}

Ashcraft MH (1992) Cognitive arithmetic: a review of data and theory. Cognition 44:75-106

Ashcraft MH (1995) Cognitive psychology and simple arithmetic: a review and summary of new directions. Math Cogn 1:3-34

Barner D, Bachrach A (2010) Inference and exact numerical representation in early language development. Cogn Psychol 60:40-62

Berch DB (2005) Making sense of number sense: implications for children with mathematical disabilities. J Learning Disabil 38(4):333-339

Briars JD, Larkin JH (1984) An integrated model of skill in solving elementary word problems. Cogn Instr 1(3):245-296

Butterworth B (2005) The development of arithmetical abilities. J Child Psychol Psychiatry 46:3-18

Carey S (2001) Cognitive foundations of arithmetic: evolution and ontogenesis. Mind Lang 16:37-55

Condry KF, Spelke ES (2008) The development of language and abstract concepts: the case of natural number. J Exp Psychol 137:22-28

Cummins DD (1991) Childrens's interpretations of arithmetic word problems. Cogn Instr 8(3):261-289

De Cruz H (2008) An extended mind perspective on natural number representation. Philosop Psychol 21:475-490

Decock L (2008) The conceptual basis of numerical abilities: one-to-one correspondence versus the successor relation. Philosop Psychol 21:459-473

Dehaene S (2001) Precis of the number sense. Mind Lang 16:16-36

Dehaene S (2003) The neural basis of the Weber-Fechner law: a logarithmic mental number line. Trends Cogn Sci 7:145-147

Dixon RMW (1980) The languages of Australia. Cambridge University Press, Cambridge

Dowker A, Bala S, Lloyd D (2008) Linguistic influences on mathematical development: how important is the transparency of the counting system? Philosop Psychol 21:523-538

Fias W (2001) Two routes for the processing of verbal numbers: evidence from the SNARC effect. Psychol Res 65:250-259

Fias W, Brysbaert M, Geypens F, d'Ydewalle G (1996) The importance of magnitude information in numerical processing: evidence from the SNARC effect. Math Cogn 2(1):95-110

Gallistel CR, Gelman R (1990) The what and how of counting. Cognition 44:43-74

Gelman R, Butterworth B (2005) Number and language: how are they related? Trends Cogn Sci 9:6-10

Giaquinto M (2001a) Knowing numbers. J Philos 98:5-18

Giaquinto M (2001b) What cognitive systems underlie arithmetical abilities? Mind Lang 16:56-68

Halberda J, Feigenson L (2008) Set representations required for the acquisition of the "natural number" concept. Behavioral Brain Sci 31:655-656

Hintikka J (1970a) The semantics of modal notions and the indeterminacy of ontology. Synthese 21:408-424 
Hintikka J (1970b) Propositional attitudes De Dicto and De Re. J Philos 67:869-883

Krysztofiak W (2008) Modalna arytmetyka indeksowanych liczb naturalnych: możliwe światy liczb. Przegląd Filozoficzny-Nowa Seria 17:79-107

Le Corre M, Carey S (2007) One, two, three, four, nothing more: an investigation of the conceptual sources of the verbal counting principles. Cognition 105:395-438

Lemaire P, Abdi H, Fayol M (1996) The role of working memory resources in simple cognitive arithmetic. Euro J Cogn Psychol 8(1):73-103

Pica P, Lemer C, Izard V, Dehaene S (2004) Exact and approximate arithmetic in an Amazonian indigene group. Science 306:499-503

Riley MS, Greeno JG, Heller JI (1983) Development of children's problem-solving ability in arithmetic. In: Ginsberg HP (ed) The development of mathematical thinking. Academic, Orlando, FL, pp 153-196

Rips LJ, Asmuth J, Bloomfield A (2006) Giving the boot to the bootstrap: how not to learn the natural numbers. Cognition 101:B51-B60

Rips LJ, Bloomfield A, Asmuth J (2008) From numerical concepts to concepts of number. Behavioral Brain Sci 31:623-687

Rosch E (1973) Natural categories. Cogn Psychol 4:328-350

Rosch E (1975) Cognitive representation of semantic categories. J Exp Psychol 104:192-233

Sellars W (1962) Naming and saying. Philos Sci 29:7-26

Semadeni Z (2008) Deep intuition as a level in the development of the concept image. Educ Studies Math 68:1-17

Spelke ES (2000) Core knowledge. Am Psychol 55:1233-1243

Spelke ES, Kinzler KD (2007) Core systems in human cognition. In: von Hofsten C, Rosander K (eds) Progress in brain research, pp 164, 257-264

Verguts T, Fias W (2008) Symbolic and nonsymbolic pathways of number processing. Philos Psychol 21:539-554

Wynn K (1990) Children's understanding of counting. Cognition 36:155-193

Wynn K (1992) Children's acquisition of number words and the counting system. Cogn Psychol $24: 220-251$

Yoshimi J (2007) Mathematizing phenomenology. Phenomenol Cogn Sci 6:271-279

Zebian S (2005) Linkages between number concepts, spatial thinking, and directionality of writing: the SNARC effect and the REVERSE SNARC effect in English and Arabic monoliterates, biliterates, and illiteratee Arabic speakers. J Cogn Culture 5(1-2):165-190 